\title{
Long-term memory for instrumental responses does not undergo protein synthesis-dependent reconsolidation upon retrieval
}

\author{
Pepe J. Hernandez ${ }^{1}$ and Ann E. Kelley \\ Department of Psychiatry and Neuroscience Training Program, University of Wisconsin-Madison, Madison, Wisconsin 53719, USA
}

\begin{abstract}
Recent evidence indicates that certain forms of memory, upon recall, may return to a labile state requiring the synthesis of new proteins in order to preserve or reconsolidate the original memory trace. While the initial consolidation of "instrumental memories" has been shown to require de novo protein synthesis in the nucleus accumbens, it is not known whether memories of this type undergo protein synthesis-dependent reconsolidation. Here we show that low doses of the protein synthesis inhibitor anisomycin (ANI; 5 or $20 \mathrm{mg} / \mathrm{kg}$ ) administered systemically in rats immediately after recall of a lever-pressing task potently impaired performance on the following daily test sessions. We determined that the nature of this impairment was attributable to conditioned taste aversion (CTA) to the sugar reinforcer used in the task rather than to mnemonic or motoric impairments. However, by substituting a novel flavored reinforcer (chocolate pellets) prior to the administration of doses of ANI (150 or 210 $\mathrm{mg} / \mathrm{kg}$ ) previously shown to cause amnesia, a strong CTA to chocolate was induced sparing any aversion to sugar. Importantly, when sugar was reintroduced on the following session, we found that memory for the task was not significantly affected by ANI. Thus, these data suggest that memory for a well-learned instrumental response does not require protein synthesis-dependent reconsolidation as a means of long-term maintenance.
\end{abstract}

Studies in a variety of species have shown that the consolidation of newly acquired memories depends on gene transcription and de novo protein synthesis (Abel and Lattal 2001). Moreover, some forms of memory, upon retrieval, seem to require a period of reconsolidation in order to preserve the memory trace (i.e., approach avoidance, fear, taste, spatial, and recognition memory in rats) (Misanin et al. 1968; Judge and Quartermain 1982; Przybyslawski and Sara 1997; Nader et al. 2000; Bozon et al. 2003; Eisenberg et al. 2003; Koh and Bernstein 2003). Although the molecular pathways leading to reconsolidation may differ from those recruited during initial consolidation (Taubenfeld et al. 2001), de novo protein synthesis is essential to both processes (Davis and Squire 1984; Debiec et al. 2002; Kida et al. 2002; Myers and Davis 2002).

Instrumental or operant learning is another fundamental form of learning, whereby an animal forms associations between its actions and the outcome of those actions in order to operate adaptively on its environment (Thorndike 1911; Skinner 1953; Rescorla 1991; Dickinson and Balleine 1994). In a common experimental model of appetitive instrumental learning, a hungry rat learns over several training sessions that it can obtain a sugar pellet by pressing a lever it has never before experienced. Memory for such action-outcome contingencies, once consolidated, is extremely robust, degrading little over time (Skinner and Ferster 1957). Where much work has focused on the acquisition of instrumental behaviors, the maintenance of memory for such tasks has yet to be well-studied within the framework of reconsolidation.

Protein synthesis inhibitors continue to be an important tool in learning and memory research. Early studies examining the action of protein-synthesis inhibitors on many types of memory have demonstrated their ability to impair consolidation

\footnotetext{
'Corresponding author.

E-mail phernand@wisc.edu; fax (608) 265-3050.

Article published online ahead of print. Article and publication date are at http://www.learnmem.org/cgi/doi/10.1101//m.84904.
}

(Davis and Squire 1984). A subset of these studies shows that protein-synthesis inhibitors impair performance on instrumental tasks after systemic or intraventricular administration (Ungerer et al. 1975; Day et al. 1977; Castro-Larrazabal et al. 1983). For example, Castro-Larrazabal et al. (1983) found that rats leverpressed fewer times following systemic injections of anisomycin (ANI) but the possibility that the impairment was due to illness was not addressed. Ungerer et al. (1975) demonstrated that systemic injections of acetoxycycloheximide decreased leverpressing in mice but the performance deficit was shown to be a conditioned taste aversion (CTA) to the food reinforcers used in the task. If the CTA was extinguished by supplementing the animals' diet with the aversive reinforcer for several days prior to the memory test, operant responding was less severely affected. This would suggest that the drug had no effect on memory; however, as the authors noted, supplying the food reinforcer outside of the learning context could have reactivated the memory trace for the task thereby counteracting any amnestic effects of the drug.

Recently, we demonstrated that de novo protein synthesis is required within the ventral striatum, specifically the nucleus accumbens (NAc), for the initial consolidation of memory for a lever-pressing task (Hernandez et al. 2002). However, once the task was well-learned, inhibition of protein synthesis within the NAc failed to affect memory for the task or its performance. One interpretation of these data is that memory for instrumental contingencies, in general, does not undergo protein synthesisdependent reconsolidation. Alternatively, it is possible that regions other than the NAc within the corticostriatal network involved in the acquisition/maintenance of instrumental behaviors (i.e., amygdala or medial prefrontal cortex) (Baldwin et al. 2000; Kelley et al. 2003) are involved in reconsolidation. To address these possibilities, we administered ANI systemically, either intraperitoneally (i.p.) or subcutaneously (s.c.), after retrieval of memory for a lever-pressing task to determine whether de novo protein synthesis is involved in the maintenance or possible reconsolidation of memory for instrumental responses. 


\section{Results}

Pilot studies were performed on rats to examine the effects of i.p. administration of $1,2.5,5,20,37.5,75$, and $150 \mathrm{mg} / \mathrm{kg}$ ANI. We found that the three high doses produced clear signs of illness within $10 \mathrm{~min}$ of injection including: lethargy (including laying on the belly), locomotor and balance impairments, and piloerection lasting for nearly $2 \mathrm{~h}$ where the $150 \mathrm{mg} / \mathrm{kg}$ dose (commonly used in the literature) (Squire and Barondes 1974; Bourtchouladze et al. 1998; Taubenfeld et al. 2001) resulted in death after one injection per day for $3 \mathrm{~d}$ in several rats. Although the 20 $\mathrm{mg} / \mathrm{kg}$ dose did not produce any obvious side effects, post-trial administration of this dose appeared to reduce operant responding. Therefore, it was necessary to characterize the nature of this impairment before any conclusions regarding memory were drawn.

In the first set of experiments, the effect of ANI on performance of an appetitive instrumental task was assessed in six groups of rats. Briefly, hungry rats were trained to press a lever for a sugar pellet reward in operant chambers during daily $15 \mathrm{~min}$ trials. Two levers were present, where only one lever produced a sugar reward when pressed. Once performance on the correct lever stabilized, signifying the task was well-consolidated, i.p. injections of ANI $(1,5$, or $20 \mathrm{mg} / \mathrm{kg})$ or saline were administered immediately post-trial following trials $10-14$. Prior to drug or saline treatments all rats were pressing at similar levels; however, rats that received 5 or $20 \mathrm{mg} / \mathrm{kg}$ ANI lever-pressed progressively fewer times after each ANI treatment relative to their respective saline-treated controls (Fig. 1). A repeated-measures analysis of variance (ANOVA) indicated a main effect of treatment for the 20 $\mathrm{mg} / \mathrm{kg}$ dose $\left(F_{(1,13)}=15.67, P=0.002\right)$ over trials $11-25$, as well as three significant interactions: trial $\times$ treatment $\left(F_{(14,182)}=12.41\right.$, $P<0.0001)$, lever $\times$ treatment $\left(F_{(1,13)}=16.08, P=0.002\right)$, and trial $\times$ lever $\times$ treatment $\left(F_{(14,182)}=12.79, P<0.0001\right)$. ANOVA also revealed a main effect of treatment for the $5 \mathrm{mg} / \mathrm{kg}$ dose $\left(F_{(1,12)}=5.10, P=0.04\right)$ over trials $11-24$, as well as trial $\times$ treatment $\left(F_{(13,156)}=3.89, P<0.0001\right)$, lever $\times$ treatment $\left(F_{(1,12)}=5.21, P=0.04\right)$, and trial $\times$ lever $\times$ treatment $\left(F_{(13,156)}=4.08, P<0.0001\right)$ interactions. No significant treatment effect was observed in the $1 \mathrm{mg} / \mathrm{kg}$ ANI dose $\left(F_{(1,12)}=0.561\right.$, $P=0.5$ ) over trials $11-25$. Thus, ANI induced a dose-dependent and progressive diminution in responding.
To determine the nature of the lever-pressing impairment observed in the first set of experiments, several control studies were conducted to assess the effects of ANI on consummatory and motoric behaviors. Experiment 2 addressed the possibility that systemic administration of ANI caused visceral malaise thereby suppressing operant responding for sugar. Six groups of rats were initially trained to lever-press as described in Experiment 1; however, after the task was acquired the levers were retracted and pre-weighed boluses of sugar were provided freely within the operant chambers in order to examine the effects of ANI on noncontingent sugar consumption. Figure 2 shows the effect of ANI $(1,5$, or $20 \mathrm{mg} / \mathrm{kg})$ or saline on sugar consumption $24 \mathrm{~h}$ after each of two i.p. injections (Test 1 and Test 2). Relative to pretreatment baseline levels of sugar consumption, rats injected with $20 \mathrm{mg} / \mathrm{kg}$ ANI consumed $38 \%$ and $70 \%$ less sugar on test trials 1 and 2, respectively, whereas the rats injected with 5 $\mathrm{mg} / \mathrm{kg}$ ANI reduced sugar consumption to a lesser extent $(21 \%$ and $47 \%$ reductions on test days one and two, respectively). ANOVA revealed a significant treatment effect $\left(F_{(1,12)}=24.95\right.$, $P=0.0003)$ and trial $\times$ treatment interaction $\left(F_{(1,12)}=28.07\right.$, $P=0.0002)$ for the $20 \mathrm{mg} / \mathrm{kg}$ group over test trials 1 and 2 ), relative to saline-treated animals. A significant treatment effect $\left(F_{1,14}=4.82, P=0.05\right)$ and trial $\mathrm{x}$ treatment interaction $\left(F_{1,14}=7.78, P=0.01\right)$ was found for the $5 \mathrm{mg} / \mathrm{kg}$ group over both test trials as well. Rats injected with $1 \mathrm{mg} / \mathrm{kg}$ ANI did not demonstrate any aversion to sugar and consumed similar amounts of sugar relative to controls throughout the treatment period $\left(F_{(1,14)}=0.05, P=0.8\right)$.

We next determined whether ANI specifically reduced the consumption of sugar causing CTA or whether food consumption, in general, was affected. In Experiment 3, rats were trained to lever-press as described above. Once performance stabilized, each rat received an i.p. injection of either $20 \mathrm{mg} / \mathrm{kg}$ ANI or saline after the next two trials. Chow consumption was measured immediately after each injection (Test 1 and Test 2 ) as well as $24 \mathrm{~h}$ after the last injection (Test 3 ) in order to measure both the acute and cumulative effects of ANI. ANOVA over test days one and two revealed no significant differences in the amount of chow consumed between ANI and saline treated rats $\left(F_{1,12}=0.26\right.$, $P=0.6$; Fig. 3). However, ANI-treated rats did consume significantly more chow than saline-treated rats $24 \mathrm{~h}$ after the last ANI
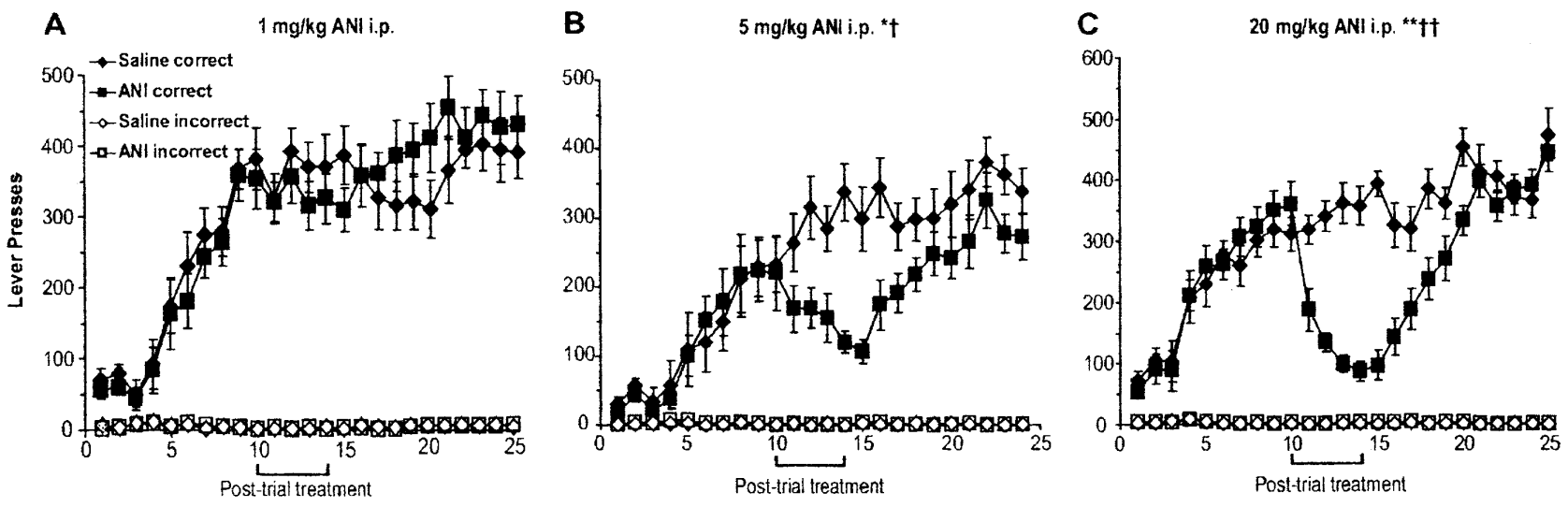

Figure 1. Post-trial intraperitoneal administration of ANI dose-dependently impairs performance of an appetitive instrumental task. (A) ANI (1 mg/kg) injected once daily for $5 \mathrm{~d}$ late in learning has no effect on operant responding. ANI group $\mathrm{n}=7$, Saline group $\mathrm{n}=7$. (B) Administration of $5 \mathrm{mg} / \mathrm{kg}$ or (C) $20 \mathrm{mg} / \mathrm{kg}$ ANI results in a significant reduction in operant responding for sugar pellets. ANI group $(5 \mathrm{mg} / \mathrm{kg}) \mathrm{n}=8$, Saline group $\mathrm{n}=7 ; 20 \mathrm{mg} / \mathrm{kg}$ ANI group $n=7$, Saline group $n=8$. Data shown as mean number \pm s.e.m. of correct (filled symbols) and incorrect (open symbols) lever-presses for each group; diamonds and squares represent Saline- and ANI- treated rats, respectively; brackets beneath the $x$-axes indicate frequency of post-trial treatments. ${ }^{*} P<0.05,{ }^{* *} P<0.01$ compared with saline. $\dagger P<0.05, \dagger \dagger P<0.01$ trial $\times$ treatment, lever $\times$ treatment, and trial $\times$ lever $\times$ treatment interactions. The key applies to the whole figure. 
A

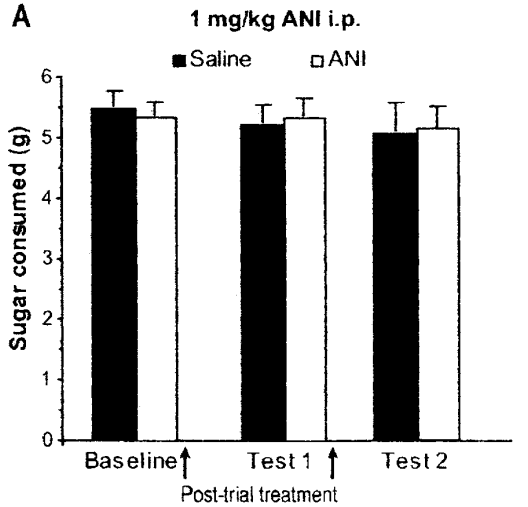

B

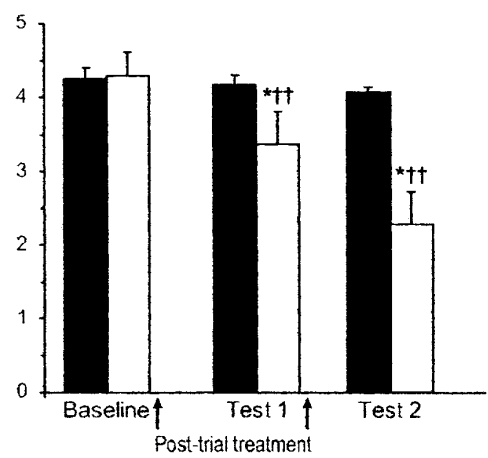

C

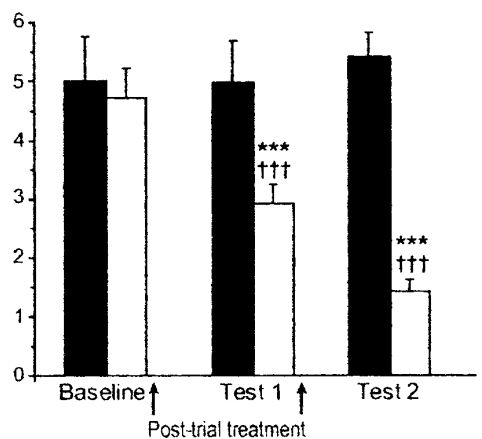

Figure 2. Intraperitoneal administration of ANI dose-dependently reduces sugar consumption suggesting the development of a conditioned taste aversion. (A) Administration of $1 \mathrm{mg} / \mathrm{kg} \mathrm{ANI} \mathrm{had} \mathrm{no} \mathrm{effect} \mathrm{on} \mathrm{sugar} \mathrm{consumption.} \mathrm{ANI} \mathrm{group} \mathrm{n}=8$, Saline group $\mathrm{n}=8$. (B) Rats injected with $5 \mathrm{mg} / \mathrm{kg}$ or (C) $20 \mathrm{mg} / \mathrm{kg}$ ANI consume progressively less sugar following each daily treatment. ANI group $(5 \mathrm{mg} / \mathrm{kg}) \mathrm{n}=8$, Saline group $\mathrm{n}=8 ; 20 \mathrm{mg} / \mathrm{kg}$ ANI group $\mathrm{n}=7$, Saline group $\mathrm{n}=7$. Data shown as amount of sugar consumed $(\mathrm{g}) \pm$ s.e.m. within a 10 min period. Arrows beneath the $x$-axes indicate post-trial treatments. ${ }^{*} P<0.05$, ${ }^{* * *} P<0.001$, compared with saline. $\dagger \dagger P<0.01,+\dagger \dagger P<0.001$, trial $\times$ treatment interaction. Filled and open bars represent Saline- and ANI-treated rats, respectively. The key applies to the whole figure.

injection (Test 3$)$ as revealed by a t-test $(t=3.3, P=0.006)$. This was consistent with the fact that ANI-treated rats developed a CTA to sugar and were therefore less sated than controls at the end of the instrumental training session. Thus, the ANI-treated rats were able to consume more during the test period following training, thereby demonstrating that chow consumption was not adversely affected by ANI.

Although sugar consumption was specifically reduced, it was possible that motor deficits could also contribute to the observed impairments in instrumental responding. Therefore, in Experiment 4, horizontal, ambulatory, and rearing activity were measured in rats trained to lever-press. All measurements were taken $24 \mathrm{~h}$ following each of two i.p. injections of $20 \mathrm{mg} / \mathrm{kg}$ ANI or saline (Test 1 and Test 2) administered immediately after instrumental training. ANOVA showed no significant differences relative to saline-treated controls in any of the locomotor measures ( $P>0.3$ in all cases; Fig. 4). Therefore, lower doses of ANI were assumed not to affect locomotor behavior and were not tested here.

The results of Experiments 1-4 demonstrate the aversive potential of low doses of systemically administered ANI, yet a much higher dose is typically used to cause amnesia $(150 \mathrm{mg} / \mathrm{kg})$. Assuming a higher dose of ANI would also cause CTA in addition to

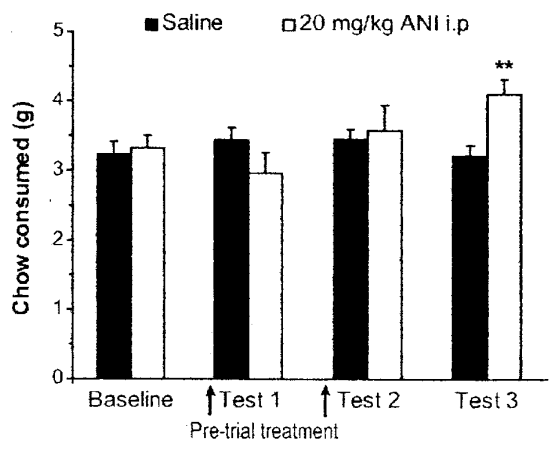

Figure 3. ANI does not produce an aversion to chow. Chow consumption was measured immediately before (Test 1 and Test 2) or $24 \mathrm{~h}$ after (Test 3) i.p. administration of $20 \mathrm{mg} / \mathrm{kg}$ ANI. ANI group $\mathrm{n}=7$, Saline group $n=7$. Data shown as amount of chow consumed (g) \pm s.e.m. within a 10 min period. Filled and open bars represent Saline- and ANItreated rats, respectively. Arrows beneath the $x$-axes indicate pre-trial treatments. ${ }^{*} P<0.01$ compared with saline. any memory impairments, it was necessary to prevent the CTA to sugar from forming so that any performance deficits would only represent memory impairments. Typically, CTA is specific for the food consumed near the time illness is induced and does not generalize to differently flavored foods (Revusky and Bedarf 1967; Bernstein 1999; Welzl et al. 2001). Therefore, in Experiment 5 an attempt was made to prevent the decrease in instrumental responding due to CTA to sugar by substituting novel chocolate flavored reinforcers during the session paired with ANI. Two groups of rats were trained to lever-press for sugar as described above except on trials 19 and 21 when they received chocolate pellets instead. Immediately after trial 19, a single i.p. injection of $150 \mathrm{mg} / \mathrm{kg}$ ANI or saline was administered and the rats were given $48 \mathrm{~h}$ to recover after which sugar was reintroduced to test memory for the task. Figure $5 \mathrm{~A}$ shows that responding, although somewhat lower than saline-treated rats, was not significantly lowered by ANI as revealed by a t-test on trial 20 $(t=-1.65, P=0.12)$. Conversely, operant responding for chocolate was dramatically reduced by ANI relative to controls. A t-test on trial 21 revealed a highly significant treatment effect of ANI on pressing for chocolate $(t=-6.62, P<0.0001)$ suggesting a CTA specific to chocolate had indeed developed. To be sure the CTA to chocolate did not generalize to sugar, two separate groups of ANI- and saline-treated rats were trained in the same fashion but $48 \mathrm{~h}$ following treatment all rats were allowed free access to pre-weighed boluses of sugar or chocolate. In the case that salinetreated rats naturally preferred the taste of chocolate to sugar pellets, half of each group received sugar whereas the other half received chocolate thereby avoiding any bias that could arise if both reinforcers were presented simultaneously. The following day each rat received the opposite reinforcer. T-tests revealed no significant differences in the amount of sugar or chocolate consumed within each treatment group between the two days ( $P>0.33$ in all cases); therefore, the data over both days for each reinforcer were combined and analyzed for differences between treatment groups. Indeed, ANI-treated rats consumed 76\% less chocolate than saline-treated rats whereas sugar consumption was unaffected (Fig. 5B). T-tests verified ANI-treated rats developed a significant CTA to chocolate $(t=-6.2, P<0.0001)$ but not to sugar ( $t=0.05, P=0.96$ ) relative to saline-treated rats.

Although i.p. administration of $150 \mathrm{mg} / \mathrm{kg}$ has been shown to prevent enough cerebral protein synthesis to impair memory consolidation and reconsolidation in some paradigms, s.c. injections of $210 \mathrm{mg} / \mathrm{kg}$ have also been successfully used to impair 

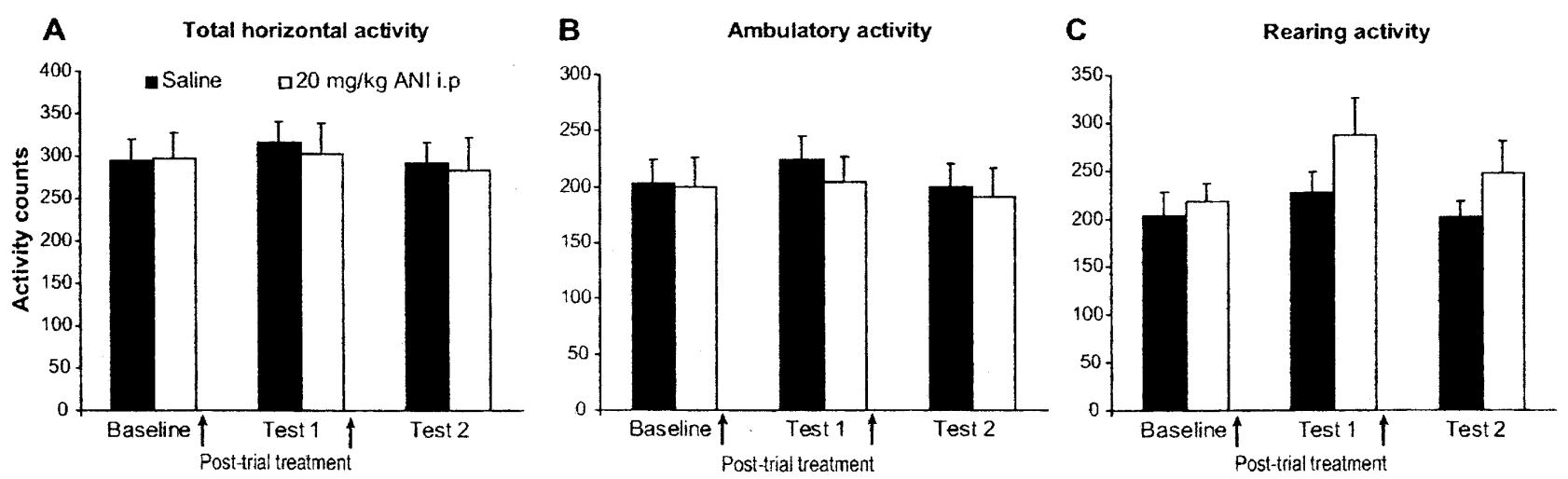

Figure 4. ANI has no effect on locomotion. Rats receiving $20 \mathrm{mg} / \mathrm{kg}$ ANI i.p. once per day for $2 \mathrm{~d}$ exhibit normal $(A)$ horizontal activity, $(B)$ ambulatory activity, and $(C)$ rearing activity. ANI group $n=7$, Saline group $n=8$. Data shown as number of activity counts \pm s.e.m. Arrows beneath the $x$-axes indicate post-trial treatments. Filled and open bars represent Saline- and ANI-treated rats, respectively. The key applies to the whole figure.

memory (Davis et al. 1980). At this dose, it has been reported that $>97 \%$ of cerebral protein synthesis is inhibited (Milekic and Alberini 2002). Therefore, in order to address the possibility that $150 \mathrm{mg} / \mathrm{kg}$ was not sufficient to impair reconsolidation, in Experiment 6 , separate groups of rats were trained exactly as described in Experiment 5 with the exception that the dose of ANI paired with chocolate was increased to $210 \mathrm{mg} / \mathrm{kg}$ and administered s.c. rather that i.p. T-tests revealed that this dose of ANI produced a strong CTA to chocolate $(t=-4.0, P=0.002)$, which did not generalize to sugar $(t=-1.5, P=0.16)$ as measured in noncontingent consumption tests. Most importantly, however, lever-pressing for sugar during the reconsolidation test was not affected by the increased dose of ANI relative to saline-treated controls $(t=-1.0, P=0.32)$ (Table 1$)$. Together, these data suggest that memory for the lever-pressing task does not, to any significant degree, depend on protein-synthesis dependent reconsolidation processes for its long-term maintenance. trary performance criterion to ensure all animals had consolidated memory for the task. This procedure also ensured similar levels of motivation to perform and provided equal exposure to the sugar reinforcers used in the task. Finally, since no particular brain region has been implicated in the reconsolidation of "instrumental memory," systemic injections (i.p. or s.c.) of ANI were administered allowing us to broadly target de novo protein synthesis within multiple regions simultaneously.

With this rationale, we show that post-trial injections of low doses of ANI progressively suppressed operant responding for sugar in a well-learned lever-pressing task. Noncontingent measures of sugar and chow consumption, as well as locomotor activity, demonstrated that ANI produced CTA specific to sugar. In all cases, a return to pretreatment levels of responding was observed once drug treatments ceased, indicating extinction of the CTA. Decreases in responding similar in magnitude resulted even if drug treatments $(20 \mathrm{mg} / \mathrm{kg})$ were delayed until after as many as 30 training sessions (data not shown), suggesting overtraining

\section{Discussion}

The present study was designed to address whether memory for an appetitive instrumental task undergoes reconsolidation upon retrieval. Previously, we have shown that de novo protein synthesis is required within the nucleus accumbens (NAc) for the initial consolidation of memory for a leverpressing task (Hernandez et al. 2002). Once the task was learned, performance no longer depended on protein synthesis within the NAc for its maintenance. We did not address the possibility, however, that protein synthesis in brain regions other than the NAc might be involved in the maintenance of memory, thus providing the impetus for the present study.

Unlike some models of learning and memory where stimulus-stimulus associations can be learned in a single trial (i.e., Pavlovian fear conditioning), instrumental learning typically develops more slowly. Due to this gradual formation of memory for response-outcome contingencies, it is more difficult to determine when, exactly, learning has occurred. Therefore, to study reconsolidation in this model, we trained all animals until peak performance levels were achieved rather than setting an arbi-

A

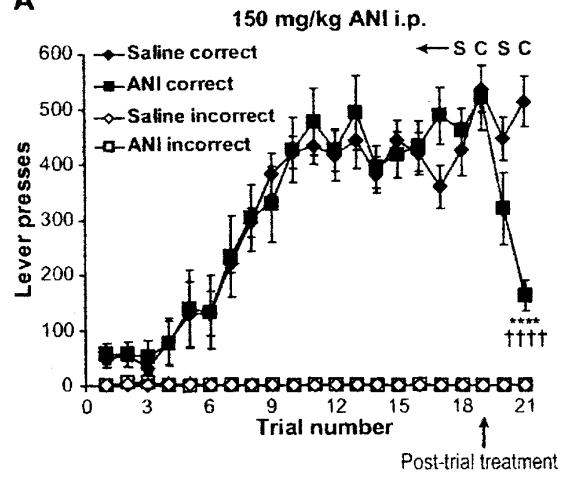

B

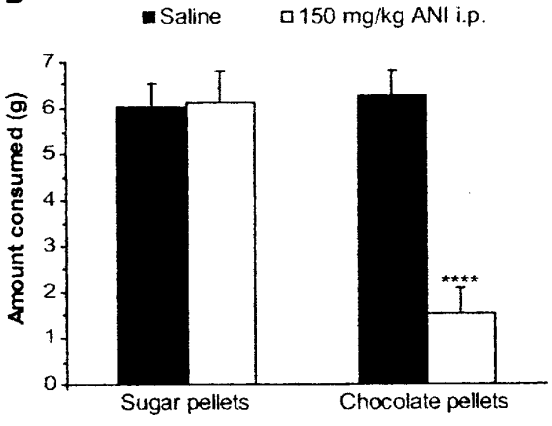

Figure 5. Responding for sugar in a lever-pressing task is not significantly affected by ANI if CTA is prevented. $(A)$ Rats initially trained to press for sugar received chocolate during trial 19 after which $150 \mathrm{mg} / \mathrm{kg}$ ANI was administered i.p. as indicated by the arrow beneath the $x$-axes. The letters $S$ or $\mathrm{C}$ above the graph represent days on which the rats responded for sugar or chocolate, respectively. Memory for the task was examined on trial 20 whereas responding for chocolate (a test of aversion for chocolate) was examined on trial 21. ANI group $n=7$, Saline group $n=7$. Data shown as mean number \pm s.e.m. of correct (filled symbols) and incorrect (open symbols) lever-presses for each group. Diamonds and squares represent Saline- and ANI- treated rats, respectively. Only responding for chocolate was significantly reduced. $(B)$ Rats trained as those above consumed significantly less chocolate whereas sugar consumption was unaffected after a single injection of $150 \mathrm{mg} / \mathrm{kg}$ ANI. Data shown as amount of sugar or chocolate consumed (g) \pm s.e.m. within a 10 min period. ANI group $n=8$, Saline group $n=8$. Filled and open bars represent Saline- and ANI-treated rats, respectively. ${ }^{\star * \star *} P<0.0001$, compared with saline (for whole figure). $\dagger_{\dagger}+\mathrm{P} P 0.0001$ trial $\times$ treatment, lever $\times$ treatment, and trial $\times$ lever $\times$ treatment interactions. 
Table 1. Effect of dose and route of administration of anisomycin on procedural memory and CTA

\begin{tabular}{|c|c|c|c|c|}
\hline \multirow[b]{2}{*}{$\begin{array}{l}\text { Injection } \\
\text { route }\end{array}$} & \multirow[b]{2}{*}{ Treatment } & \multirow{2}{*}{ 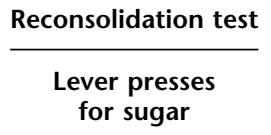 } & \multicolumn{2}{|c|}{ Taste aversion test } \\
\hline & & & $\begin{array}{c}\text { Sugar } \\
\text { consumed (g) }\end{array}$ & $\begin{array}{c}\text { Chocolate } \\
\text { consumed (g) }\end{array}$ \\
\hline s.c. & $\begin{array}{l}\text { Saline } \\
\text { ANI }(210 \mathrm{mg} / \mathrm{kg})\end{array}$ & $\begin{array}{l}393 \pm 27 \\
343 \pm 39\end{array}$ & $\begin{array}{l}5.59 \pm 0.36 \\
4.46 \pm 0.54\end{array}$ & $\begin{array}{l}3.73 \pm 0.80 \\
0.01 \pm 0.00^{\star}\end{array}$ \\
\hline i.p. & $\begin{array}{l}\text { Saline } \\
\text { ANI }(150 \mathrm{mg} / \mathrm{kg})\end{array}$ & $\begin{array}{l}446 \pm 40 \\
319 \pm 66\end{array}$ & $\begin{aligned} & 6.07 \pm 0.48 \\
& 6.12 \pm 0.69 \\
& * t=-4.03, P=0.002\end{aligned}$ & $\begin{array}{c}6.28 \pm 0.53 \\
1.53 \pm 0.55^{\star *} \\
* * t=-6.2, P<0.0001\end{array}$ \\
\hline
\end{tabular}

Similar to the effects of i.p. ANI administration, s.c. administration of a higher dose of AN1 did not produce amnesia for the lever-pressing task but induced a significant CTA for chocolate that did not generalize to sugar. Data comparing the effects of subcutaneous (s.c. $210 \mathrm{mg} / \mathrm{kg}$ ) and intraperitoneal injections (i.p., $150 \mathrm{mg} / \mathrm{kg}$ ) of ANI on memory for lever pressing and taste aversion are expressed as the number of correct presses \pm s.e.m. and $g$ consumed \pm s.e.m., respectively. ANI was injected immediately after the last lever-pressing session. The reconsolidation test for lever-pressing and taste aversion tests occurred $48 \mathrm{~h}$ after ANI administration. $\mathrm{n}=6$ for Saline- and ANI-treated groups that received s.c. injections in both the reconsolidation and taste aversion experiments. See Figure 5 legend for i.p. group details.

and latent inhibition (attenuation of an aversion due to extensive pre-exposure to the reinforcer) have limited control over the sensitivity of operant responding to the aversive effects of ANI. It has long been realized that factors other than amnesia could influence performance in tasks designed to assess memory (Booth and Simson 1973). In fact, CTA has been demonstrated in mice that have received amnestic doses of anisomycin, cycloheximide, and acetoxycycloheximide (Squire II et al. 1975; Ungerer et al. 1975). Here we extend these findings by showing that in rats even very low doses of ANI are capable of inducing a profound CTA to an appetitive reinforcer used in an instrumental task.

Yet, in order to address whether memory for this task is reconsolidated after retrieval, much higher doses of ANI (150 or $210 \mathrm{mg} / \mathrm{kg}$ ) were used to ensure enough protein synthesis was inhibited to produce amnesia. However, these doses are not welltolerated, causing obvious signs of illness. Thus, both toxicity and CTA had to be overcome in order to dissociate any putative drug-induced memory impairments from ANI's adverse side effects. In doing so, unfamiliar chocolate pellets were substituted for sugar immediately prior to ANI treatment after which the rats were allowed two days to recover. Then, on the following session, sugar was replaced in order to assess memory for the task without the confounding effects of CTA. Similar procedures have been used to attenuate aversions to a familiar flavor by inducing CTA to a novel flavor (Revusky 1971; Cannon et al. 1985), although none have used a protein synthesis inhibitor as the illnessinducing agent. Figure 5, A and B, together with Table 1 demonstrate that high doses of ANI delivered by two different routes (i.p. or s.c.) did not significantly lower operant responding for sugar relative to saline-treated rats, but caused a dramatic decrease in responding for chocolate due to the development of a specific CTA. In fact, the higher s.c. dose had no noticeable effect on responding for sugar during the reconsolidation test, whereas the lower-dose i.p. injection of ANI nonsignificantly lowered responding for sugar. This could be due to a nonspecific effect of i.p. injections of ANI (i.e., irritation of the mucosal lining of the peritoneal cavity) not present when the drug is administered s.c. Finally, it may seem somewhat paradoxical that ANI failed to cause amnesia for the learned aversion to chocolate. However, this effect might be expected if the drug-induced malaise persists longer than the peak levels of protein synthesis inhibition needed to cause amnesia. Indeed, CTA can be induced after long delays (several hours) between consumption of a food and subsequent illness (Rozen 1969; Bures and Buresova 1979).

The fact that high levels of responding were maintained
(>300 lever presses; Fig. 5A and Table 1) after receiving an amnestic dose of ANI, regardless of the route of administration, provides strong evidence that memory for the lever-pressing task was not affected. Together with our previous work demonstrating the requirement for de novo protein synthesis during the initial consolidation of instrumental memory, the present results parallel those of Milekic and Alberini (2002) who showed that memory for an inhibitory avoidance task becomes progressively less dependent on protein synthesis after recall over time (Milekic and Alberini 2002). It is possible that early in learning (i.e., during the first few trials) memory for the task may undergo several rounds of consolidation followed by reconsolidation, but these data suggest that as the behavior is overtrained the animal depends less on de novo protein synthesis for the long-term maintenance of the memory. Alternatively, it may be possible that memory for an overtrained behavior undergoes reconsolidation but we were unable to disrupt this process using the present approach. However, it would seem more adaptive to not reconsolidate procedural memories after performance of the skill has become proficient.

Although several types of memory may undergo a period of instability initiated by retrieval, here we show that memory for a well-consolidated instrumental task is relatively resistant to the effects of protein synthesis inhibition suggesting that reconsolidation is not a major mechanism by which this form of memory is maintained over long periods of time. Much evidence suggests the genomic alterations critical for positive reinforcement and memory formation are likely to be the same mechanisms affected by "habit-forming" drugs of abuse (Hyman and Malenka 2001; Nestler 2001). Therefore, understanding the mechanisms that confer long-term stability to memory for instrumental responses may have broad implications in the treatment of drug addiction.

\section{Materials and Methods}

\section{Animals}

A total of 173 male Sprague-Dawley rats (300-325 g) (Harlan Sprague Dawley) were housed in groups of two on a $12 \mathrm{~h}$ light/ dark cycle. To minimize stress, all rats were handled regularly prior to behavioral procedures. Rats were food deprived and maintained at $85 \%$ of their free-feeding weight in all experiments. Animal care was in accordance with University of Wisconsin-Madison Animal Care and Use guidelines and the NIH Guide.

\section{Learning \& Memory}




\section{Apparatus}

Operant chambers (Coulbourn Instruments) equipped with two retractable levers, a house light, and a food trough with photosensors, were used in all experiments. Stimulus events and data acquisition were controlled by micro-computer (Lablinc, Coulbourn).

\section{Drugs}

Anisomycin (Sigma) was diluted in sterile 0.9\% saline and dissolved in $2 \mathrm{~N} \mathrm{HCl}$ and bought to $\mathrm{pH} \sim 7$ with $2 \mathrm{~N} \mathrm{NaOH}$. All doses of ANI were formulated so that each rat received $\sim 0.25 \mathrm{ml}$ injection volumes. Control rats received equal injection volumes of sterile $0.9 \%$ saline. The 150 and $210 \mathrm{mg} / \mathrm{kg}$ doses of ANI were chosen based on their capacity to inhibit a large degree of cerebral protein synthesis $(>90 \%)$ resulting in amnesia in both mice and rats (Squire and Barondes 1974; Bourtchouladze et al. 1998; Taubenfeld et al. 2001; Milekic and Alberini 2002).

\section{Behavioral procedures}

\section{Instrumental training}

In all experiments, animals were habituated to the operant chambers for $3 \mathrm{~d}$ with sugar pellets ( $45 \mathrm{mg}$; BioServe) present in the food trough then trained once daily. During each $15 \mathrm{~min}$ trial, pressing the correct lever resulted in the following sequence of stimuli: house light offset at the same time as a red signal light onset, followed $1 \mathrm{~s}$ later by delivery of a sugar pellet to the food trough on a fixed ratio one schedule (every lever-press dispensed one pellet) for the first 50 reinforcements followed by a variable ratio two schedule for the remainder of the trial, such that, on average two lever-presses were required to receive a sugar pellet. Responding on the incorrect lever had no programmed consequences. Whether the correct lever was the left or right lever was counterbalanced within groups. To expedite learning, crushed sugar was placed on the correct lever for the first $2 \mathrm{~d}$. Total responses on correct and incorrect levers were recorded. Nosepokes into the food trough were also recorded (data not shown) but generally tended to track the profile of instrumental responding, as shown in our previous studies (Kelley et al. 1997; SmithRoe and Kelley 2000). Rats were trained to asymptotic levels of responding ( $\sim$ trial 10) on the correct lever to ensure the task was well-learned before drug treatments began. All treatments were administered i.p. or s.c. immediately post-trial. In Experiment 1, i.p. treatments consisted of ANI $(1,5$, or $20 \mathrm{mg} / \mathrm{kg}$ ) or saline administered after trials 10-14. No drug was administered on subsequent trials. Each dose of ANI was compared to its own saline-treated group ( $\mathrm{n}=6-8$ for each group).

\section{Consumption tests for sugar and chow}

In Experiment 2, all rats were trained in the instrumental task, as described above, to insure similar levels of food deprivation and experience with sugar relative to the animals in Experiment 1. After asymptotic rates of lever-pressing were achieved, the rats were given $10 \mathrm{~min}$ of free access to $6 \mathrm{~g}$ of sugar pellets placed in the food trough of the operant chambers with the levers retracted. The amount of sugar consumed was recorded for several days in order to establish a stable baseline of consumption after which the rats received an injection of ANI $(1,5$, or $20 \mathrm{mg} / \mathrm{kg})$ or saline (i.p.) on two consecutive days. Each dose of ANI was compared to its own saline-treated group ( $n=7-8$ for each group). The amount of sugar eaten was measured $24 \mathrm{~h}$ after each injection in order to determine if ANI caused a decrease in sugar consumption. In Experiment 3, separate groups of rats, also trained to lever-press, were used to determine whether ANI affected consumption of the chow used in their daily feeding regimen. Once performance on the levers had stabilized, rats were injected i.p. with $20 \mathrm{mg} / \mathrm{kg}$ ANI $(\mathrm{n}=7)$ or saline $(n=7)$ after each of two additional sessions, then placed separately into empty cages identical to their home cages and given $10 \mathrm{~min}$ of free access to $11 \mathrm{~g}$ of chow. A third measure of chow consumption was taken $24 \mathrm{~h}$ after the second i.p. injection in order to assess the effects of multiple injections of ANI while not under the direct influence of the drug.

\section{Locomotor behavior}

In Experiment 4, rats were trained to lever-press as described above; however, before each habituation or training session locomotor activity was measured. Clear, polycarbonate activity cages $(48 \times 25 \times 20 \mathrm{~cm})$ equipped with four infrared photobeams spaced at regular intervals lengthwise along the bottom were used to measure both horizontal activity (any beam break) and ambulatory activity (consecutive beam breaks) (San Diego Instruments). Eight additional photobeams spaced evenly along the top width of the cages measured rearing activity (vertical activity). Data were collected by microcomputer in 5 min intervals totaling $30 \mathrm{~min}$ beginning at $1200 \mathrm{~h}$ each day. After asymptotic levels of instrumental responding were achieved, post-trial injections of $20 \mathrm{mg} / \mathrm{kg}$ ANI $(n=7)$ or saline $(n=8)$ were administered i.p. following the next two sessions. Locomotor activity was measured $24 \mathrm{~h}$ after each injection in order to reproduce and assess any nonspecific motor effects ANI may have caused during the instrumental learning experiments.

\section{CTA attenuation/reconsolidation test}

In order to evaluate whether memory for the lever-pressing task undergoes reconsolidation, an attempt was made in Experiments 5 and 6 to dissociate the aversive and putative amnestic effects of the drug. Since ANI (150 mg/kg i.p. and $210 \mathrm{mg} / \mathrm{kg}$ s.c.) has been shown to inhibit enough cerebral protein synthesis to interfere with memory consolidation as tested $48 \mathrm{~h}$ after administration, two important changes were made to the training and testing procedures to accommodate their use. In Experiment 5, two groups of rats were trained to lever-press for sugar, as above, but with trials occurring every $48 \mathrm{~h}$ rather than daily allowing more time for the ANI treated rats to recover from the toxic effects of the drug. Additionally, a novel flavored reinforcer (chocolate flavored pellets) was substituted for sugar on trial 19 after which $150 \mathrm{mg} / \mathrm{kg}$ ANI $(\mathrm{n}=7)$ or saline $(\mathrm{n}=7)$ was administered i.p. immediately post-trial. Memory for the lever-pressing task was assessed $48 \mathrm{~h}$ later on trial 20 again using sugar as the reinforcer. No sugar or chocolate was supplied outside of the operant chambers. An additional trial was included (trial 21) to assess the effect of ANI on operant responding for chocolate. If the aversion seen previously to sugar was successfully circumvented by this method of training, we reasoned that any ANI-induced decrease in lever pressing would be due to a memory impairment rather than conditioned aversion. To verify that a condition taste aversion to chocolate developed and whether the aversion generalized to sugar, separate groups of rats were trained in the same fashion (ANI, $n=8$; Saline, $n=8$ ) except that on the test days after ANI or saline treatment the rats were placed separately into empty cages identical to their home cages and given $10 \mathrm{~min}$ to eat $8 \mathrm{~g}$ of sugar or chocolate pellets. A choice test commonly used to calculate an aversion index (Dragoin et al. 1971; Grote and Brown 1971) was not administered but rather half of each group received chocolate where the other half received sugar. The following day each animal received the opposite reinforcer. Aversion was measured in this fashion due to the possibility that saline-treated rats might naturally prefer chocolate to sugar. If this were the case, it would not be possible to determine the degree to which CTA might generalize to sugar thus complicating the interpretation of any possible decrease in lever-pressing during the reconsolidation test.

Experiment 6 was conducted in the same fashion as Experiment 5 with the exception that the dose of ANI was increased to $210 \mathrm{mg} / \mathrm{kg}$ and the route of injection was s.c. rather than i.p. Four separate groups of rats ( $n=6$ per group) were used for the reconsolidation and noncontingent consumption tests.

\section{Statistical analysis}

Data from the instrumental learning experiments were analyzed by multifactorial analysis of variance (ANOVA). The betweensubjects factor was treatment and the repeated-measures factors 
were lever and trial. Data prior to ANI treatment in these experiments were not included in the analysis. Where appropriate ttests were used. Accepted significance level was set at $P<0.05$ in each case.

\section{Acknowledgments}

This work and P.J.H. were supported by grant \#DA04788 from the National Institute on Drug Abuse.

\section{References}

Abel, T. and Lattal, K.M. 2001. Molecular mechanisms of memory acquisition, consolidation and retrieval. Curr. Opin. Neurobiol. 11: $180-187$

Baldwin, A.E., Holahan, M.R., Sadeghian, K., and Kelley, A.E. 2000. $\mathrm{N}$-methyl-D-aspartate receptor-dependent plasticity within a distributed corticostriatal network mediates appetitive instrumental learning. Behav. Neurosci. 114: 84-98.

Bernstein, I.L. 1999. Taste aversion learning: A contemporary perspective. Nutrition 15: 229-234.

Booth, D.A. and Simson, P.C. 1973. Aversion to a cue acquired by its association with effects of an antibiotic in the rat. J. Comp. Physiol. Psychol. 84: $319-323$.

Bourtchouladze, R., Abel, T., Berman, N., Gordon, R., Lapidus, K., and Kandel, E.R. 1998. Different training procedures recruit either one or two critical periods for contextual memory consolidation, each of which requires protein synthesis and PKA. Learn. Mem. 5: 365-374.

Bozon, B., Davis, S., and Laroche, S. 2003. A requirement for the immediate early gene zif268 in reconsolidation of recognition memory after retrieval. Neuron 40: 695-701.

Bures, J. and Buresova, O. 1979. Neurophysiological analysis of conditioned taste aversion. In Brain mechanisms in memory and learning: From the single neuron to man (ed. M.A.B. Brazier), pp. 127-138. Raven Press, New York.

Cannon, D.S., Best, M.R., Batson, J.D., Brown, E.R., Rubenstein, J.A., and Carrell, L.E. 1985. Interfering with taste aversion learning in rats: the role of associative interference. Appetite 6: 1-19.

Castro-Larrazabal, G., Colotla, V.A., and Rojas-Ramirez, J.A. 1983. Effects of anisomycin on performance under a fixed ratio schedule (FR 25). Proc. West Pharmacol. Soc. 26: 193-196.

Davis, H.P. and Squire, L.R. 1984. Protein synthesis and memory: A review. Psychol. Bull. 96: 518-559.

Davis, H.P., Rosenzweig, M.R., Bennett, E.L., and Squire, L.R. 1980. Inhibition of cerebral protein synthesis: Dissociation of nonspecific effects and amnesic effects. Behav. Neural. Biol. 28: 99-104.

Day, T.A., Overstreet, D.H., and Schiller, G.D. 1977. Centrally administered cycloheximide in rats: Behavioural concomitants and modulation of amnesic effects by biogenic amines. Pharmacol. Biochem. Behav. 6: 557-565.

Debiec, J., LeDoux, J.E., and Nader, K. 2002. Cellular and systems reconsolidation in the hippocampus. Neuron 36: 527-538.

Dickinson, A. and Balleine, B. 1994. Motivational control of goal-directed action. Anim. Learn. Behav. 22: 1-18.

Dragoin, W., McCleary, G.E., and McCleary, P. 1971. A comparison of two methods of measuring conditioned taste aversions. Behav. Res. Methods Instrum. 3: 309-310.

Eisenberg, M., Kobilo, T., Berman, D.E., and Dudai, Y. 2003. Stability of retrieved memory: Inverse correlation with trace dominance. Science 301: $1102-1104$.

Grote, F.W. and Brown, R.T. 1971. Conditioned taste aversions: Two-stimulus tests are more sensitive than one-stimulus tests. Behav. Res. Methods Instrum. 3: 311-312.

Hernandez, P.J., Sadeghian, K., and Kelley, A.E. 2002. Early consolidation of instrumental learning requires protein synthesis in the nucleus accumbens. Nat. Neurosci. 5: 1327-1331.

Hyman, S.E. and Malenka, R.C. 2001. Addiction and the brain: The neurobiology of compulsion and its persistence. Nat. Rev. Neurosci. 2: 695-703.
Judge, M.E. and Quartermain, D. 1982. Characteristics of retrograde amnesia following reactivation of memory in mice. Physiol. Behav. 28: $585-590$.

Kelley, A.E., Smith-Roe, S.L., and Holahan, M.R. 1997. Response-reinforcement learning is dependent on $\mathrm{N}$-methyl-D-aspartate receptor activation in the nucleus accumbens core. Proc. Natl. Acad. Sci. 94: 12174-12179.

Kelley, A.E., Andrzejewski, M.E., Baldwin, A.E., Hernandez, P.J., and Pratt, W.E. 2003. Glutamate-mediated plasticity in corticostriatal networks: Role in adaptive motor learning. Ann. N.Y. Acad. Sci. 1003: $159-168$.

Kida, S., Josselyn, S.A., de Ortiz, S.P., Kogan, J.H., Chevere, I., Masushige, S., and Silva, A.J. 2002. CREB required for the stability of new and reactivated fear memories. Nat. Neurosci. 5: 348-355.

Koh, M.T. and Bernstein, I.L. 2003. Inhibition of protein kinase A activity during conditioned taste aversion retrieval: Interference with extinction or reconsolidation of a memory? Neuroreport 14: 405-407.

Milekic, M.H. and Alberini, C.M. 2002. Temporally graded requirement for protein synthesis following memory reactivation. Neuron 36: 521-525.

Misanin, J.R., Miller, R.R., and Lewis, D.J. 1968. Retrograde amnesia produced by electroconvulsive shock after reactivation of a consolidated memory trace. Science 160: 554-555.

Myers, K.M. and Davis, M. 2002. Systems-level reconsolidation: Reengagement of the hippocampus with memory reactivation. Neuron 36: 340-343.

Nader, K., Schafe, G.E., and Le Doux, J.E. 2000. Fear memories require protein synthesis in the amygdala for reconsolidation after retrieval. Nature 406: 722-726.

Nestler, E.J. 2001. Molecular basis of long-term plasticity underlying addiction. Nat. Rev. Neurosci. 2: 119-128.

Przybyslawski, J. and Sara, S.J. 1997. Reconsolidation of memory after its reactivation. Behav. Brain Res. 84: 241-246.

Rescorla, R.A. 1991. Associative relations in instrumental learning: The eighteenth Bartlett memorial lecture. Q. J. Exp. Psychol. B. 43: 1-23.

Revusky, S.H. 1971. The role of interference in association over a delay. In Animal Memory (eds. W.K. Honig and P.H.R. James), pp. 155-213. Academic Press, New York, London.

Revusky, S.H. and Bedarf, E.W. 1967. Association of illness with prior ingestion of novel foods. Science 155: 219-220.

Rozen, P. 1969. Central or peripheral mediation of learning with long CS-US intervals in the feeding system. J. Comp. Physiol. Psychol. 67: 421-429.

Skinner, B.F. 1953. Science and Human Behavior. Free Press, New York.

Skinner, B.F. and Ferster, C.B. 1957. Schedules of Reinforcement. Appleton-Century-Crofts, New York.

Smith-Roe, S.L. and Kelley, A.E. 2000. Coincident activation of NMDA and dopamine D1 receptors within the nucleus accumbens core is required for appetitive instrumental learning. J. Neurosci. 20: $7737-7742$.

Squire, L.R. and Barondes, S.H. 1974. Anisomycin, like other inhibitors of cerebral protein synthesis, impairs 'long-term' memory of a discrimination task. Brain Res. 66: 301-308.

Squire II, L.R., Emanuel, C.A., Davis, H.P., and Deutsch, J.A. 1975. Inhibitors of cerebral protein synthesis: Dissociation of aversive and amnesic effects. Behav. Biol. 14: 335-341.

Taubenfeld, S.M., Milekic, M.H., Monti, B., and Alberini, C.M. 2001. The consolidation of new but not reactivated memory requires hippocampal C/EBPbeta. Nat. Neurosci. 4: 813-818.

Thorndike, E. 1911. Animal intelligence; experimental studies. Macmillan, New York.

Ungerer, A., Marchi, D., Ropartz, P., and Weil, J.H. 1975. Aversive effects and retention impairment induced by acetoxycycloheximide in an instrumental task. Physiol. Behav. 15: 55-62.

Welzl, H., D'Adamo, P., and Lipp, H.P. 2001. Conditioned taste aversion as a learning and memory paradigm. Behav. Brain Res. 125: 205-213.

Received February 20, 2004; accepted in revised form October 5, 2004. 


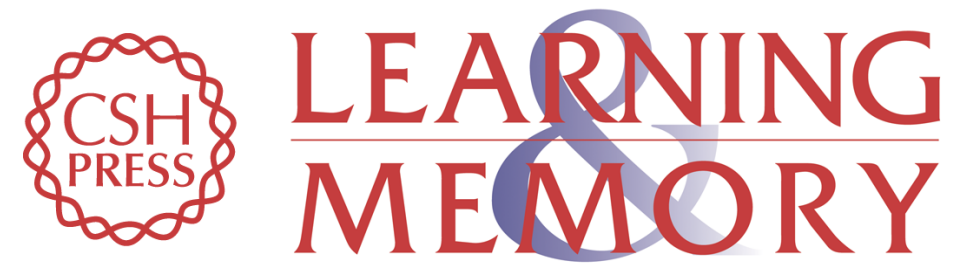

\section{Long-term memory for instrumental responses does not undergo protein synthesis-dependent reconsolidation upon retrieval}

Pepe J. Hernandez and Ann E. Kelley

Learn. Mem. 2004, 11:

Access the most recent version at doi:10.1101//m.84904

References This article cites 35 articles, 6 of which can be accessed free at: http://learnmem.cshlp.org/content/11/6/748.full.html\#ref-list-1

License

Email Alerting Receive free email alerts when new articles cite this article - sign up in the box at the Service top right corner of the article or click here. 